\title{
Vorwort zur 5., neu bearbeiteten und erweiterten Auflage
}

Die erste Auflage dieses Arbeitshefts erschien 1983. Seit der Erstauflage gab es drei unveränderte Neuauflagen. Die vorliegende 5. Auflage wurde um ein Kapitel zum Thema Sprechaktsequenzen erweitert. Die übrigen Kapitel wurden an einigen Stellen überarbeitet. Die Literaturhinweise wurden aktualisiert.

Der Text konnte über längere Zeit unverändert bleiben, da sich die wesentlichen Positionen innerhalb der Theorie der Sprechakte, sofern sie für Linguisten relevant sind, nicht entscheidend geändert haben. ${ }^{1}$

In die vorliegende Überarbeitung musste lediglich die Auffassung von Searle/Vanderveken (1985) hinsichtlich der Beschreibung der performativen Äußerungen bzw. der Sprechaktklasse der Deklarationen aufgenommen werden. Da diese Theorie aber keine ungeteilte Zustimmung gefunden hat, kann auch in diesem Falle nicht davon gesprochen werden, dass sich grundsätzliche Positionen innerhalb der sprechakttheoretischen Diskussion verschoben hätten.

Die Sprechakttheorie wird in vielen Gebieten, die sich mit Sprache beschäftigen, mit Erfolg angewendet wie z.B. der Literaturanalyse, der Sprachdidaktik, der Theologie, Rechtsphilosophie usw. Die vorliegende Einführung kann keinen Überblick über diese vielfältigen Anwendungsgebiete geben. Das hätte den Umfang einer Einführung überschritten. Das Arbeitsheft hat auch nicht den Anspruch, die wissenschaftsgeschichtliche Entwicklung der Sprechakttheorie nachzuzeichnen. Es geht vielmehr um eine Darstellung der grundlegenden Einsichten der Sprechakttheorie und um die Skizzierung eines Ansatzes, der es erlaubt eine systematische Darstellung der sprachlichen Mittel zu geben, mit denen man sprachliche Handlungen vollziehen kann. In Gegensatz zu einer philosophischen Beschäftigung mit Sprechakten darf eine linguistische Sprechakttheorie auf eine Einbeziehung der Äußerungsformen und die Erfassung ihrer grammatischen Eigenschaften nicht verzichten.

Mein Dank gilt meinen Studenten, die mit mir in den Seminaren über den Text diskutiert haben. Einige der Änderungen in der vorliegenden Auflage gehen auf ihre Kritik zurück.

G. Hindelang

Münster, im August 2009

1 Eine ähnliche Einschätzung vertritt auch Harras (2004, Vorwort). 